\title{
Trajetória Profissional J.J. Coury e a difusão do ideário moderno arquitetônico no Triângulo Mineiro
}

\author{
Maria Eliza Alves Guerra
}

\section{Resumo}

O trabalho objetiva abordar e demonstrar a importância da produção urbanísticas do arquiteto João Jorge Coury (1940/1970), nos projetos de espaços públicos para a cidade de Uberlândia/MG e região do Triângulo Mineiro, em um período de euforia nacional, com a construção de Brasília. Destaca-se a influência de Lúcio Costa, Corbusier e Roberto Burle Marx na formação de Coury. Pretende-se assim contribuir para ampliar a análise e compreensão da construção do pensamento moderno não só das "obras representativas" de nossos arquitetos da "fase heróica" dos centros hegemônicos do Brasil, mas do interior do país, onde muitos profissionais através da arquitetura, urbanismo e paisagismo acrescentaram elementos conceituais, formais e estruturais que o moderno instaurou em um contexto preciso: o do processo de modernização.

\section{Palavras-chave}

arquitetura e urbanismo modernos, espaços públicos, urbanização regional.

\section{Abstract}

This is paper's objective is to demonstrate the importance of the architect João Jorge Coury's body of work (1940/1970), developing public spaces projects in the city of Uberlândia/MG and all over the Triângulo Mineiro region, during a period of nationwide euphoria, the construction of Brasília. Important it is to emphasize the influence of architects such as Lúcio Costa, Corbusier, and Roberto Burle Max in Coury's professional formation. The goal is contributing to expand the analysis and understanding of the modern architecture thinking conception not only regarding the "representative work" of our architecture from the "heroic phase" at the hegemonic centers of Brazil, but from Brazil's countryside as well, where many architects, urbanists and landscaping professional implemented conceptual, formal and structural elements, that modern architecture established in a specific context: the modernization process.

\section{Keywords}

modern architecture and urbanism, public spaces, regional urbanization. 


\section{Introdução}

São pontos comuns no século XX, a expansão industrial, a presença do estado e a crescente urbanização nos países latinos americanos que reflete em sua produção arquitetônica e urbanística. O esforço desprendido nas últimas três décadas por pesquisadores da área de história da arquitetura e do urbanismo no Brasil e na América Latina resulta em um real enriquecimento de novas abordagens e significativos avanços metodológicos na diversificação de temas, sobretudo em relação à circulação de idéias, compreendida enquanto trocas e transferências.

O final da década de 1970 significou na arquitetura brasileira a retomada dos debates, que com a redemocratização do país, em 1985 ampliaram-se, a partir das pesquisas acadêmicas, na tentativa de compreender o período pré e pós-Brasília numa perspectiva histórica, convergindo a um tema recorrente: a construção de Brasília foi um marco na arquitetura brasileira.

A repercussão da construção de Brasília (1957/1960), através de sua divulgação em revistas nacionais e internacionais impactou países latinos e europeus. Brasília, uma cidade nova no coração do Brasil, projetada de acordo com os ideais urbanísticos da arquitetura moderna, era um símbolo de transformações profundas, instituiu a idéia de planejamento; visando a ocupação do interior do país e significou para os arquitetos grandes possibilidades de atuação e consolidação da nossa arquitetura, que desde a década anterior, já era reconhecida internacionalmente e instituída hegemonicamente no Brasil.

A constatação desta repercussão e de seu significado no Brasil e na América Latina tem sido objeto de investigações mais profundas atualmente, com o distanciamento temporal e ideológico necessário, o que permite uma revalorização da arquitetura moderna brasileira.

Brasília também significou uma reversão nos rumos políticos do país, pela quebra de expectativas políticas e arquitetônicas pactuadas anteriormente, sob a bandeira do nacional-desenvolvimentismo, viabilizado pelo Presidente Juscelino Kubitschek com o consenso em torno de uma causa a "união nacional" na crença do progresso e no desenvolvimento.

Como contribuição aos estudos que abrangem este período, este artigo se propõe a discutir os desafios que a arquitetura brasileira enfrentou ao se consolidar, não só com as "obras representativas de nossos arquitetos da fase heróica", de centros hegemônicos do Brasil, mas com a produção arquitetônica presente no interior do país - região denominada Brasil Central - pautada em uma base documental, reflexão e 
análise das referidas propostas e obras que eram desconhecidas, negligenciadas ou colocadas como "obra menor" pela historiografia brasileira.

Em termos de localização geográfica é importante frisar que o termo Brasil Central foi usual para designar a região Centro Oeste que abrangia: Triângulo Mineiro, regiões de Goiás e do Mato Grosso. Simbolicamente presente ao longo do século XX pela política de integração nacional e deslocamento de fronteiras que visaram à retomada do lema bandeirante da "Marcha para o Oeste", cujo destaque como "ponta de lança" foi à construção de Goiânia (1933/37), durante o primeiro Governo de Getúlio Vargas, que governou o país, em dois períodos (1930/1945 e 1950/54). Esta política foi consolidada pelo Presidente Juscelino Kubitschek (1956/1961) com a efetivação da prioridade de seu Plano de Metas que era a construção de Brasília. As duas cidades projetadas em tempos diferentes contaram com a mão-de-obra e, inicialmente o suporte comercial necessário aos seus empreendimentos a partir de Uberlândia e região do Triângulo Mineiro, Alto Paranaíba, etc. Uberlândia/MG dista 400 km de Brasília/DF e 360 km de Goiânia/GO.

Portanto, antes de Brasília, a região já havia presenciado a construção da cidade de Goiânia na década de 1930 para ser a nova capital do Estado de Goiás e, a partir de 1955 a conviver não só com a construção da nova Capital Federal, mas com a implantação da infra-estrutura necessária para sua viabilização, com a construção de grandes hidrelétricas em seus principais rios, o Rio Grande e Rio Paranaíba, com conseqüentes inundações de povoados e terras agricultáveis, remoções de populações ribeirinhas e construções de novas vilas operadoras e cidades, implantação de uma vasta malha rodoviária, ampliação das redes de telecomunicações e setores de segurança, entre outros que constavam do Plano de Metas.

\section{Relevância profissional}

Neste artigo será abordado; a relevância da produção do arquiteto João Jorge Coury ${ }^{1}$ (1908/1970) que foi um difusor dos conceitos de arquitetura e urbanismo modernos na região, desde a década de 1940 e, que sediado na cidade de Uberlândia/MG, atuou durante trinta anos em toda região, sendo o único escritório de arquitetura estabelecido na cidade até a segunda metade da década de 1950.

Atuou nas cidades de Uberlândia, Uberaba, Goiânia, Anápolis, Itumbiara, Goiandira, Centralina, Monte Alegre, Campina Verde, Capinópolis, Ituiutaba, Prata, Tupaciguara, Araguari, Brasília, São Sebastião do Paraíso, Iturama, entre outras, com projetos

\footnotetext{
${ }^{1}$ GUERRA, M. E. A. As "Praças Modernas" de João Jorge Coury no Triângulo Mineiro, Dissertação de Mestrado, EESC/USP, São Carlos, 1998.
} 
diversificados: residências, lojas, hospitais, clubes, escolas, cinemas, igrejas, fóruns, prefeituras, etc. Foi constatado apenas um edifício vertical em Uberlândia. Fato curioso, visto que a cidade, neste momento iniciava seu processo de verticalização.

Sua prática profissional na área urbanística e paisagística em Uberlândia se dá através de planos urbanísticos, destaca-se: o Bairro Roosevelt (1951), O Clube campestre Caça e Pesca, integrado a um loteamento (1962), a Cidade Industrial, englobando áreas destinadas a instalação de indústrias, bairro residencial, comercial e parque formando um anel de proteção entre indústrias e bairros adjacentes (1961), A Praça dos Três Poderes (1962), que não foi executado e a orla do Rio Paranaíba em Itumbiara/GO), parcialmente construída e praças, especialmente a Praça Tubal Vilela localizada em Uberlândia (1959/62), que Ihe granjeou grande notoriedade como urbanista e paisagista e convites para elaborar reformas ou novas praças em cidades vizinhas, independentemente se as administrações eram progressistas ou conservadoras e será objeto de análise deste texto.

A trajetória de Coury sempre esteve associada à participação ativa dentro do quadro social brasileiro, em um momento de busca de identidade para a construção do país. A sua trajetória profissional esteve intimamente ligada a sua trajetória política. Sua produção foi objeto de pesquisas na década de 1990, com duas dissertações de mestrado, uma abordando sua obra residencial em Uberlândia e outra sua atuação urbanística, com destaques para o expressivo número de praças projetadas e construídas em diversas cidades e, encontram-se listadas em referências bibliográficas. Sua produção continua objeto de pesquisas específicas na FAUeD Faculdade de Arquitetura e Urbanismo e Design da Universidade Federal de Uberlândia, visto a abrangência de sua produção em algumas cidades, que ainda não foram alvo de levantamento sistematizado e análise.

Em 2002 foi homenageado pelo IAB/MG - Instituto de Arquitetos do Brasil/ Departamento de Minas Gerais, através da 9a Premiação de Arquitetura de Minas Gerais 2002 - Arquiteto João Jorge Coury com destaque na Revista Aqui cujo editorial valoriza sua produção:

"Pouco conhecido fora do Triângulo Mineiro, Coury merece ser visto como um dos grandes arquitetos modernistas mineiros, pelo escopo de sua obra extensa e elegante. Formado na UFMG ainda nos anos 30 Coury nos traz, entre tantos exemplos, a força de uma carreira dedicada à possibilidade de uma arquitetura brasileira de qualidade." (REVISTA AQUI, Editorial, 2002) 
A atuação do arquiteto Coury pode ser analisada em dois momentos. Inicialmente ao longo da década de 1940 com as limitações técnicas que a região impunha, porém com o entusiasmo gerado pelo final da Segunda Guerra e pelo término do Regime do Estado Novo. Período que consolidou a transição nas artes e na arquitetura. Mais que uma simples transição, estas transformações criaram na realidade uma somatória de modificações conceituais, formais e estruturais que o "moderno" instaurou.

O segundo momento, a partir da discussão da mudança da Capital Federal, e que envolve todo o Triângulo Mineiro. A sociedade começa a absorver essas novas linguagens arquitetônicas ligadas à proposta de um governo desenvolvimentista.

O ideário moderno presente em Brasília refletiu na urbanização da região centrooeste, que até então, apresentava baixa densidade populacional, sua construção caracterizou-se como um período de euforia nacional. Para a região significou um acelerado crescimento econômico, refletindo na dinâmica social e cultural das cidades, em um processo de reconfiguração territorial e urbanização, sobretudo, para a cidade de Uberlândia, que se firmava enquanto pólo comercial, devido sua localização estratégica enquanto percurso entre as regiões centro-oeste-sul e que, será fortalecida com a solidificação da malha rodoviária.

A década de 1950 esta associada a mudanças socioeconômicas significativas na realidade brasileira - a chamada modernização defendida pelas lideranças políticas, movimentos culturais e artísticos e instituições científicas de produção teórica. Assim vamos assistir a explosão da cultura de massa; do rádio, TV, jornais, revistas, além do teatro, cinema, das artes plásticas, da música e principalmente da arquitetura. É a política de conciliação ideológica, com uma forte atuação da "esquerda", principalmente na vida cultural do país, onde figuram grande parte dos arquitetos atuantes desde as décadas anteriores.

Período de busca de consolidação da arquitetura e urbanismo moderno, a partir da reinterpretação de técnicas e materiais, do domínio tecnológico, de maior acuidade técnica, e esmero construtivo. Em nível internacional o pós-guerra traz profundas discussões em relação à reconstrução e revitalização das cidades destruídas pela guerra, cidade dispersa pelo zoneamento funcional, principalmente nos países em reconstrução. Neste sentido o VIII Congresso do CIAM (1951) realizado em Hoddesden, na Inglaterra ao tratar do "coração da cidade" indica que a cidade precisa ser repensada e, sobretudo seu "centro vital". No Brasil trata-se de construir cidades, de ocupar o interior do país, de intervir em espaços públicos, incluindo a questão da praça cívica. A Praça dos Três Poderes em Brasília será uma referência. Como será constatado em um estudo de Coury para uma praça cívica em Uberlândia. 


\section{Primeiro momento: formação acadêmica/atuação política}

O arquiteto João Jorge Coury, nasceu em Abadia dos Dourados/MG, cidade localizada a 140 km de Uberlândia, em 25 de novembro de 1908 e faleceu em 03 de janeiro de 1970 em Uberlândia, quando a cidade contava com 111.000 habitantes.

O inicio das atividades do escritório do arquiteto, em 1940 coincide com o período em que a cidade de Uberlândia, que à época contava com 22.123 habitantes em sua área urbana, vai se inserir no comércio nacional, com uma diversificada e intensa atividade comercial no setor de serviços, e incremento no setor industrial, pautado no incentivo à agropecuária.

Uberlândia sempre manteve um discurso progressista de crescimento e modernização, ressaltando o ideário de cidade ordeira e moderna, através dos melhoramentos em infraestrutura urbana, como esgoto, iluminação, pavimentação de ruas e de seus espaços públicos. O comércio se tornou fundamental na economia do município, devido à logística de escoamento através dos sistemas rodo/ferroviário e o intercâmbio com os centros industrializados do país, e com as cidades da região.

A diversificação de serviços criou condições para que a cidade recebesse inúmeros profissionais liberais em várias áreas de atuação. É neste momento que o arquiteto Coury vai se estabelecer na cidade, com idéias socialistas no campo político, e propostas modernas em relação à arquitetura.

O arquiteto Coury fez parte de uma geração, assim como Oscar Niemeyer, João Batista Vilanova Artigas, Sylvio Vasconcellos, dentre outros, que desde a década de 1930 esteve comprometida com o processo de modernização e, com o PCB - Partido Comunista Brasileiro. Militante desde o período de estudante foi um dos fundadores do PCB - Partido Comunista no Brasil em Uberlândia, em 1945, onde exerceu o cargo de Secretário de Divulgação e posteriormente, Secretario Geral do Partido/MG. Coury foi Integrante da primeira turma de arquitetos pioneiros em Minas Gerais, oriundo da EABH - Escola de Arquitetura de Belo Horizonte, que iniciou seu curso em 1931 e formou-se em 1937, colando grau somente em 1940, ano em que iria fixar-se na cidade de Uberlândia.

Enquanto estudante participou nos momentos inicias de uma vanguarda arquitetônica em Belo Horizonte, integrou o grupo que criou o Diretório Acadêmico em 1933, foi redator da primeira revista de arquitetura e urbanismo de Minas Gerais, "Arquitetura" em 1935, cujo objetivo era chamar a atenção para a função social do arquiteto. Expôs no Salão Bar Brasil, em 1936, considerada a Semana de Arte Moderna Mineira. 
A EABH (atualmente denominada, Escola de Arquitetura da UFMG) foi a primeira escola de arquitetura do Brasil desvinculada das Escolas Politécnicas e Belas Artes. Porém, seu quadro de docentes era basicamente composto por arquitetos formados na Escola nacional de Belas Artes, do Rio de Janeiro e por engenheiros com formação nas Politécnicas de Belo Horizonte e do Rio de Janeiro, estas pautadas no ideal Saintsimoniana e no positivismo heterodoxo, que tinha como missão "levar o progresso ao país e a intervir nas cidades, ora em transição" (SALGUEIRO, 1997). Na aula inaugural desta primeira turma, o Professor Aníbal Pinto de Matos utiliza um discurso positivista ao se referir aos futuros arquitetos, como: "os transformadores das cidades mineiras, os defensores do progresso" (GUERRA, 1998). É esta "missão" que percebemos na prática profissional de nossos pioneiros.

O curso tinha a duração de seis anos e se propunha a formar Engenheiro Arquiteto. $O$ currículo do curso $^{2}$ contemplava disciplinas como Urbanismo e Arquitetura Paisagística. Era comum a escola organizar viagens de estudo para diversas cidades como o Rio de Janeiro, São Paulo, Porto Alegre, Buenos Aires, entre outras e estimular os alunos a exporem seus projetos de conclusão de curso, sendo que alguns já apresentavam conceitos modernos. Os novos rumos que a arquitetura estava tomando nos países europeus, Estados Unidos e também no Brasil, na década de 1930, chegavam até os estudantes através das páginas de revistas que a escola assinava.

É recorrente a constatação que Le Corbusier foi referência, na primeira metade do Século XX de grande parte dos arquitetos atuantes no país, em Minas não foi diferente, como explicitado abaixo. No caso de Coury, posteriormente em um interrogatório ${ }^{3}$, consta a seguinte afirmação em relação às suas convicções:

(...) em arquitetura, segue a teoria de Le Corbusier, de aspectos mais funcional, misturado com idéias de Lúcio Costa, que se bate pela nacionalização do modernismo arquitetônico (...) que o interrogado apesar de ser tachado de comunista tem sido procurado constantemente pela elite desta cidade, para a confecção de projetos de suas residências. (RIBEIRO, 1998)

Diversas pesquisas confirmam como a primeira geração européia de arquitetos modernos foram importantes na formação dos estudantes da Escola de Arquitetura de

\footnotetext{
2 Ver a respeito RIBEIRO, P. P.A. A Difusão da Arquitetura Moderna em Minas - O arquiteto J.J. Coury em Uberlândia, cap. 1, item 1.1 A Escola de Arquitetura de Belo Horizonte. Dissertação de Mestrado, EESC/USP, São Carlos, 1998.

3 Depoimento de J.J. Coury em 15/06/1964 no 30 Batalhão de Caçadores em Uberlândia - Arquivo do extinto DOPS, atualmente acervo da Coordenação Geral da Secretaria de Estado de Segurança Pública /MG.
}

URBANA, V.5, no 7, out.2013 - Dossiê: Urbanistas e Urbanismo: a escrita da história... - CIEC/UNICAMP 
Minas Gerais na década de 1930, com grande destaque para a influência de Le Corbusier, que conheciam através de revistas como L'Architecture D' Aujourd hui (França) e Achitetural Records (EUA). O arquiteto Raphael Hardy Filho, que foi colega de Coury no curso, posteriormente Professor e Diretor da EABH, em entrevista afirmou que; "L'Architecture D' Aujourd hui foi quem influenciou sua geração e Le Corbusier, com uma nova visão de arquitetura, foi quem mostrou uma nova direção" (RIBEIRO,1998).

Nas pesquisas efetivadas ficou evidenciado que Coury lia muito e que era um profissional bem informado e, que em seu escritório mantinha livros voltados aos estudos sociais, livros de arte e arquitetura. Comprovamos a presença de: La Ville Radieuse e Obra Aberta e Obras Completas (1946-1952) de Le Corbusier; A leitura Crítica de Le Corbusier, de Pietro Maria Bardi; Arquitetura Social de Richard Neutra (1948); Brazil Builds' de Philip Goodwin (1943); Os Ismos de Ramon Gomes de La Seven (1943), Jardins de Hoje, de Germano Zimber; Construções Civis, de Alexandre Alburqueque, entre outros.

A trajetória de Coury sempre esteve associada a uma participação ativa dentro do quadro social brasileiro. Figura carismática, polêmica e ativa na vida política e cultural de Uberlândia, atuou em entidades de classe, colaborou em jornais, incentivou a produção artística na cidade, o teatro e a criação da União Estudantil Secundarista de Uberlândia, A sua trajetória profissional está intimamente ligada a sua trajetória política e, mantinha contato com outros arquitetos ligados à esquerda, entre eles: Luis Saia e Vilanova Artigas. Devido suas atividades políticas, foi preso em diversas ocasiões. Entre outras, em 1937 na onda repressiva do Estado Novo e na onda repressiva resultante do golpe militar de 1964, encaminhado para a Base da Aeronáutica de Lagoa Santa/MG onde ficou preso durante três meses. Ao retornar à Uberlândia sua atuação se restringe ao seu escritório até a sua morte.

Os escritórios de arquitetura sempre exerceram um papel importante para a formação do profissional. O escritório de Coury, além de ser ponto de encontro de uns poucos intelectuais locais, como o Professor Nelson Cupertino, Frei Egydio Parisi, o ator Mario Roquete, e os artistas plásticos, Gleber Gouveia, Juarez Magno e Geraldo Queiroz.

Coury ao introduzir uma nova linguagem nos projetos públicos e privados, influenciou jovens estudantes, que iam trabalhar em seu escritório, porque gostavam de desenhar, se apaixonavam pela profissão, e muitos decidiram estudar arquitetura. Destacamos os arquitetos: Milton Leite que atua em Uberlândia, Fernando Galvão em Goiânia, Ivan Cupertino, que atuou em Belo Horizonte e Miguel Juliano que atuou em São Paulo. 
Ao longo de uma década sua produção foi voltada para o cliente privado, com uma produção que incluía na maioria das vezes reformas e acréscimos, inicialmente com uma linguagem eclética, formalmente dominada pelo neocolonial. Linguagem presente na produção inicial de arquitetos que posteriormente romperam com esta linguagem, no advento de uma linguagem moderna, como Oscar Niemeyer, Lúcio Costa, Gregori Warchavchik, etc. que enfrentaram um mercado pouco receptivo no inicio da década de 1930 nas cidades onde atuavam como o Rio de Janeiro e São Paulo. As dificuldades referentes à aquisição de materiais de construção e ao domínio tecnológico dificultaram a introdução de uma nova linguagem arquitetônica, aliada ao fato de ainda dominar no país o debate sobre o ecletismo.

\section{Segundo momento: difusão e consolidação de sua produção}

É somente na década de 1950 que o arquiteto vai introduzir um vocabulário arquitetônico moderno e inédito na região em seus projetos residenciais, e que Brasília, como citado anteriormente viria confirmar. É quando consolida e diversifica sua produção, tendo o poder público como cliente e uma atuação em nível regional, com projetos na área de arquitetura, urbanismo e paisagismo. Brasília também vai popularizar para a sociedade a figura do arquiteto enquanto profissional, através de Oscar Niemeyer e Lúcio Costa. Coury vai se beneficiar deste momento. É um arquiteto moderno que pode oferecer projetos modernos à sociedade que se identifica com um país em busca de inovações.

Os investimentos no setor da construção civil, com a industrialização ou importação de novos materiais, para atender Brasília vai refletir em sua intensa produção, quando poderá dispor de tecnologia e materiais até então de difícil aquisição, conciliando com materiais locais a busca de uma linguagem própria, presentes em seus projetos residenciais e institucionais e, aprimorada ao se associar ao Engenheiro chileno Rodolfo Ochoa em 1954, que contribuiu tecnicamente através da execução de obras e da elaboração de projetos estruturais que passam a acompanhar os projetos arquitetônicos.

Em seus projetos residenciais em consonância com os novos conceitos de morar que o movimento moderno preconiza, propõe novos programas e novas formas de implantação, em uma década que o automóvel se populariza e passa a fazer parte do cotidiano, incorporando a linguagem de seus espaços públicos a uma arquitetura não monumental de suas residências, que permite a utilização de seus espaços livres integrados entre si, a começar pela incorporação da garagem próxima a rua, criação de pátios, acessos, circulações, áreas de lazer e estar, com o uso do jardim, que terão 
outro significado, buscando uma relação de intimidade e de uso efetivo com o usuário, valorizando pontos de interesse, estabelecendo referencias, com o uso de murais artísticos e o contraste volumétricos dos canteiros.

O conceito frente-fundo desaparece, importa integrar ambiente da casa com ambiente rua e calçada, com a valorização plástica da fachada, através da elevação de volumes em relação ao solo, brise-soleils, materiais naturais e murais. A busca da arquitetura brasileira, desde a década de 1930, com a construção do MEC caracterizou-se pela riqueza formal pelo material utilizado e por um efeito de síntese das artes. A chamada síntese das artes era um dos objetivos do movimento moderno, que buscou incentivar a colaboração entre artistas e arquitetos. Brasília confirmou essa possibilidade.

A interação arte/arquitetura é notada em várias obras residenciais de Coury, que conta com a colaboração do Artista Plástico urbelandense, Geraldo Rodrigues de Queiroz (1916/1958) na elaboração de "murais" com temas abstratos e figurativos, relacionados aos motivos nacionais ou história afetiva do morador. O mesmo não acontece em suas praças, possivelmente pela morte prematura de seu colaborador.

Neste período o "jardim" constitui um elemento definidor do projeto arquitetônico residencial de Coury, definindo uma série de tipologias. Inicialmente tímido no recuo frontal passa a se integrar internamente a casa, em suas laterais e fundo do lote, não mais caracterizados como área de serviços. Nesta interação cidade/casa, os jardins com vegetação nativa envolvem a edificação e se apresentam em curvas sinuosas valorizando o piso, usualmente em pedra portuguesa branca e preta, formando desenhos gráficos, bem como a inserção de banco contínuo, elemento urbano marcante que estarão presentes em seus projetos de praças. No final da década de 1950 percebe-se uma estreita relação entre seus projetos residenciais com as praças projetadas.

\section{Projetos urbanísticos}

A prática do arquiteto urbanista e paisagista será demonstrada na elaboração do paisagismo integrado ao desenho urbano, que é inerente a organização espacial. Solução que exige adequações funcionais, técnicas e percepção para permitir liberdade formal. Dentre do conjunto da obra de Coury, as praças são de fundamental importância para se compreender sua visão ideológica com a vida moderna e o urbano moderno.

Entre a extensa produção urbanística de Coury destacam-se seus projetos de praças, por apresentarem inovações, com proposições originais, expressivas e audaciosas na resolução de espaços com características comuns, resultante de um urbanismo que 
marcou muito a história do traçado das cidades do Triângulo Mineiro e sul de Goiás: o traçado xadrez, em que a praça é um quarteirão ou um pedaço dele.

O projeto para a Praça Tubal Vilela vai materializar novos conceitos para espaços públicos, que mais tarde vão ser difundidos por toda região, quando Coury teve a oportunidade de projetar várias praças, grandes ou pequenas, em contextos diversificados, mas com uma linguagem elaborada a partir da Praça Tubal Vilela (Figura1), que será destacada enquanto análise. Em Uberlândia projetou doze praças, além da Praça Tubal Vilela, destaca-se a Praça Nossa Senhora Aparecida.

Ressaltam-se as diversas praças existentes no Triângulo Mineiro, entre elas, as localizadas em cidades vizinhas, caso de Araguari/MG com duas praças: Praça Manuel Bonito e Praça Getúlio Vargas, em Ituiutaba/MG; a Praça Cônego Ângelo (FIGURA 2), em Tupaciguara/MG; a Praça Raul Carneiro, em Monte Alegre de Minas/MG; a Praça Dr. Adilon G. Mendonça, em Prata/MG; a Praça Juscelino Kubitschek e na cidade goiana de Itumbiara/GO; a Praça da Republica. Estes exemplos estabelecem referências, a partir de uma análise formal, estrutural e urbanística da praça associada à difusão do Movimento da Arquitetura Moderna no Brasil, mais precisamente com o paisagismo de Roberto Burle Marx. 


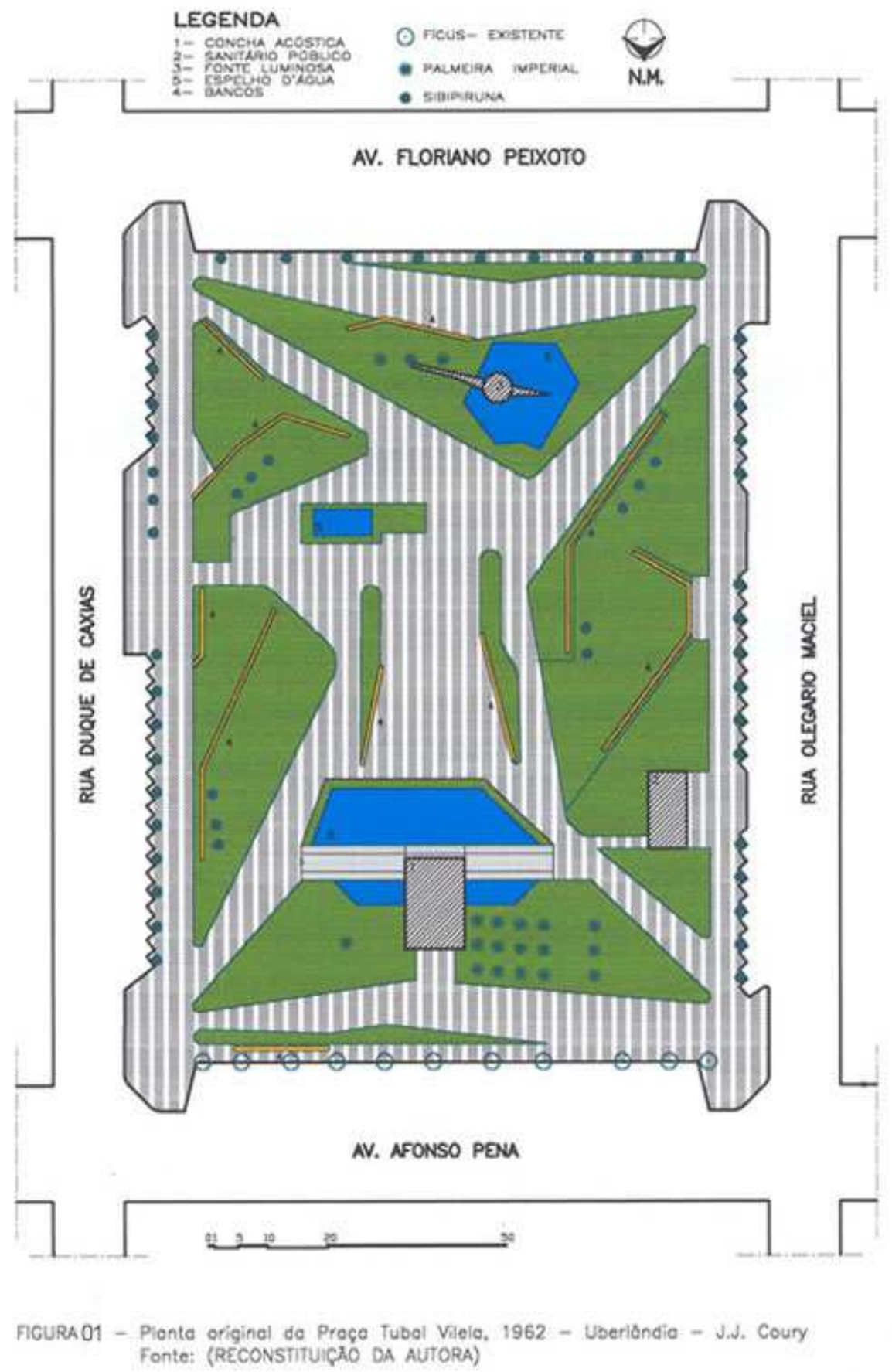

FIGURA 1 - Praça Tubal Vilela - Projeto com centro livre e marcante paginação de piso. FONTE: Arcevo da autora. 2001 

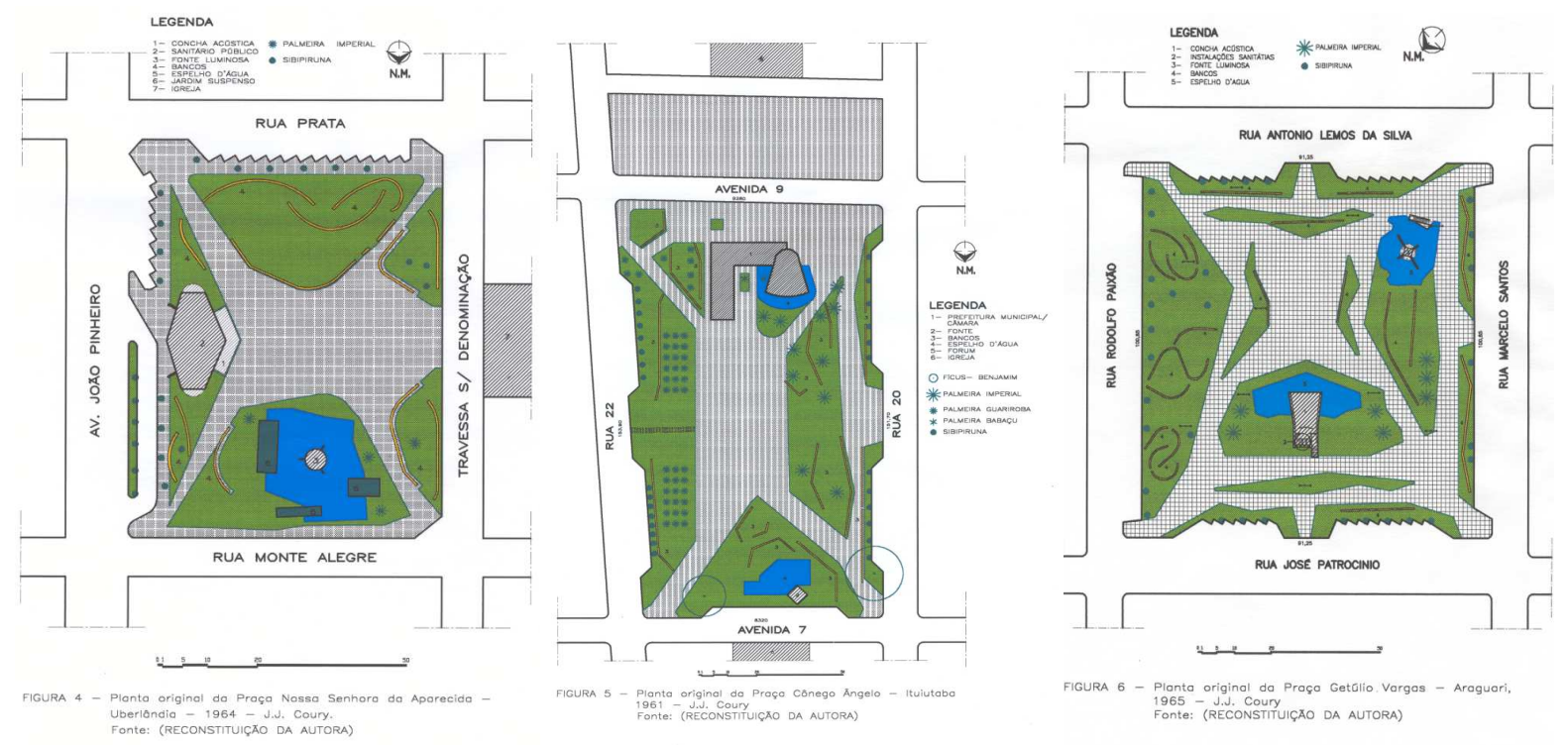

FIGURA 2 - Praça Na Sa Aparecida/Uberlândia - Pç Cônego Ângelo/Ituiutaba - Pç. Getulio Vargas/Araguari.

FONTE: Reconstituição e Acervo da autora, 2001

Porém, nem sempre a praça estará limitada a uma quadra. É o caso de um estudo elaborado para a construção de uma Praça Cívica abrangendo uma grande área, onde atualmente se encontra a Praça Sergio Pacheco, o Departamento Municipal de Água e Esgoto - DMAE, o Terminal Central, o Fórum Abelardo Penna e áreas residenciais. Estes terrenos seriam desapropriados de particulares, somados às áreas remanescentes da transferência dos trilhos da ferrovia para a região norte, em área na época, ainda não urbanizada, através do sistema de comodato para o Município. A transação condicionava ao Poder Municipal efetuar a ligação viária, entre o centro e a zona norte e possibilitava a implantação de um "Centro Cívico", localizado em lugar estratégico da cidade.

Apesar da transação entre Município e Companhia Mogiana de Estrada de Ferro (atual Ferrovia Centro-Atlântica) só ter sido efetuada oficialmente em 1970, o assunto remete a década anterior, quando Coury, em 1962, elaborou uma proposta urbanística a pedido do Prefeito Geraldo Mota Batista Ladeira (1959/63) em parceria com o Arquiteto José Geraldo de Camargo e o Engenheiro Rodolfo Uchoa.

O estudo contemplou uma área triangular (FIGURA 3), delimitada pelo prolongamento das avenidas Afonso Pena e Vasconcelos Costa e Avenida João Pessoa, que necessitaria de um grande volume de desapropriações para atender ao programa proposto: Prefeitura, Câmara Municipal, prédios para acolher o Fórum e as Coletorias (receitas estadual e federal), cartórios, hotel, teatro municipal, praça com fonte e 
monumento, áreas de lazer e rodoviária, que assim como em Brasília estaria localizada sob um viaduto, ligando as Avenidas Buenos Aires (atual João Naves de Ávila) e Monsenhor Eduardo.

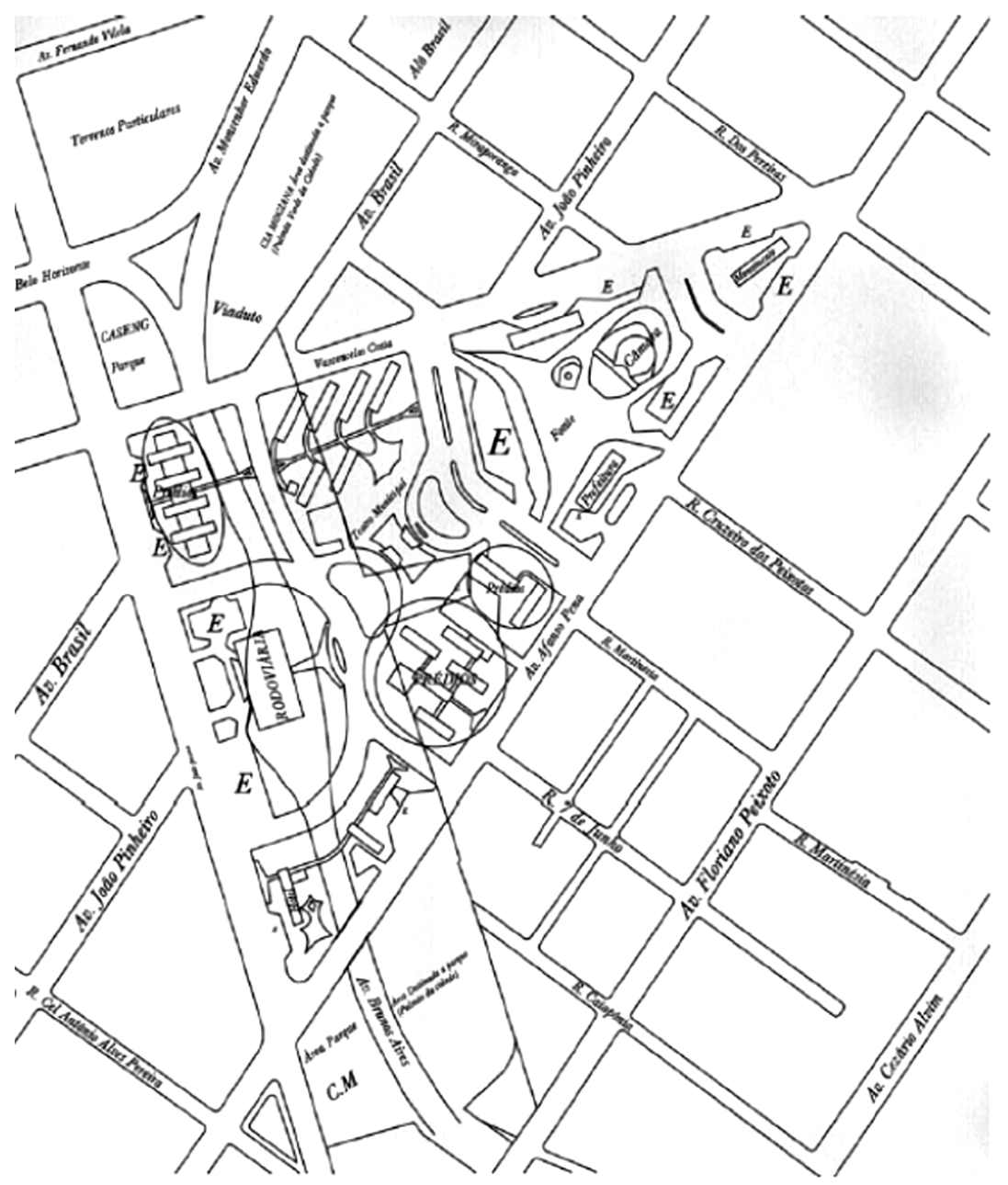

FIGURA 3 - Estudo para Praça dos três Poderes, 1962.

FONTE: LOPES, 2001

Percebe-se o traço característico do arquiteto no conjunto, principalmente no centro livre da grande praça, onde se localizam a prefeitura e a câmara. Apesar de não estar indicado, é provável que ao lado esquerdo da mesma (não indicado na planta) a intenção tenha sido a localização do fórum, que é o elemento que falta para definir uma praça cívica, já que o próprio Coury refere-se a esta proposta como, "Praça dos três Poderes" ${ }^{1}$ em uma alusão direta à Brasília (GUERRA, 1998). Em frente à praça, interrompida por uma larga via, o Teatro Municipal ocupa um lugar de destaque, ladeado por conjuntos de edifícios, enquanto a rodoviária está centralizada na Avenida 
João Pessoa, entre o hotel e outros conjuntos de edifícios. Este projeto não foi implantado, porém foi projetada concomitantemente à Praça Tubal Vilela, onde se percebe uma mesma linguagem projetual.

Quando a pesquisa foi realizada, não houve acesso ao projeto. Sendo que posteriormente (LOPES, 2001) localizou o referido projeto no arquivo da Secretária de Obras da Prefeitura de Uberlândia, reproduzido acima. Observa-se uma imensa área triangular que não coincide com área posteriormente desapropriada, denominada Praça Sérgio Pacheco e alvo de uma acirrada disputa política e objeto de outros dois projetos urbanísticos ${ }^{4}$, o primeiro em 1972 projetado por uma equipe de arquitetos locais: Elifas Martins, Arlen Simão e Paulo de Freitas, o segundo, em 1973 projetado pelo escritório carioca de Ary Garcia Roza e o já consagrado, Roberto Burle Marx.

\section{A Praça Tubal Vilela}

Como destacado anteriormente, no $8^{\circ}$ Congresso do CIAM, o tema principal a "core" e o ágora grego, são evocados por todos "onde os cidadãos eram ao mesmo tempo atores e espectadores" (ARANTES, 1993). A praça moderna como espaço democrático. E é no ágora grego, que Coury vai buscar informações para os seus projetos. Como espaço consagrado o ágora e o fórum romano, de onde se origina a praça ocidental, é de grande importância para a leitura e a compreensão do tema.

Para se compreender a importância das praças de Coury será apresentada, a seguir uma leitura da Praça Tubal Vilela, a fim de elucidar sua concepção projetual, que de certo modo estará presente em todas as outras praças, de acordo com sua localização e características particulares. Este projeto foi elaborado para substituir a praça eclética existente no local.

Com o perfil ideológico socialista João Jorge Coury, concebe a Praça Tubal Vilela, como um espaço de convivência e manifestação pública, através de uma proposta, onde o centro livre "ágora" sobressai na sua organização enquanto parcelamento, que é enfatizado através da forte paginação do piso, e dos acessos em "xis" diagonais que convergem das esquinas para este centro.

A Praça Tubal Vilela (1958/62), foi projetada com a colaboração dos arquitetos: Ivan Rodrigues Cupertino e Sebastião da S. Almeida e os irmãos/engenheiros: Rodolfo e Roberto Ochoa. Localizada no centro da cidade de Uberlândia, apresenta topografia plana e suave inserida na malha urbana, em um quarteirão de forma retangular (102x142m), com $14.484 \mathrm{~m}^{2}$. A praça se encontra delimitada à noroeste pela Avenida 
Afonso Pena, à sudeste pela Avenida Floriano Peixoto, duas avenidas importantes na cidade, enquanto circulação, e por se posicionarem no sentido norte/sul, além de apresentarem um grande uso comercial e de serviços, à sudoeste pela rua Olegário Maciel onde está situado o Colégio Estadual Bueno Brandão, e à noroeste pela rua Duque de Caxias, onde se encontra a Igreja de Santa Terezinha. Seu entorno se caracteriza por usos diversificados com comércio variado, lojas de departamento, agências bancarias, hotéis, escola estadual e residências.

Ao fazermos uma leitura da Praça, utilizando as referências morfológicas da organização de partes por meio de uma borda (não como um elemento edificado, tipo muro, parede, etc.), mas através do uso correto da vegetação, que determina uma permeabilidade do espaço com relação ao entorno. A vegetação está presente setorizada, como um elemento de controle que ordena a relação aparentemente casual entre os volumes situados na praça.

Um programa diversificado com equipamentos comunitários, tais como: concha acústica, fonte sonoro-luminosa, espelhos d'água, instalações sanitárias, grandes bancos contínuos e a resolução dos estacionamentos ampliam seus conceitos arquitetônicos, aliado à funcionalidade.

A organização proposta determina as setorizações que pode ser definida pelos elementos construídos, ou definida pelo paisagismo buscando tirar partido dos três níveis de abordagem: forrações, arbustos e árvores, que sugerem as possibilidades cênicas e volumétricas entre piso, barreiras e coberturas.

Ao utilizar os elementos construídos, e a paisagem artificial como a sibipiruna, árvore alta e frondosa, e palmeira-imperial com tronco longo e copa cerrada, permite que se possa tirar partido dos aspectos visuais, e explorar a visibilidade decorrente desta verticalidade. A utilização destas espécies, onde a floração ou porte tende a se valorizar em conjunto, criam marcos visual e, sobretudo amenizam o clima quente e seco da região. Assim como Burle Marx, utiliza espécies da flora brasileira, valorizando e difundindo a vegetação adequada ao local e ao clima.

Esta organização em torno do centro livre qualifica o espaço aberto por seu relativo afastamento da rua, criando um ambiente definido e mais delimitado, onde as fortes paginações gráficas sobre o piso, com faixas dispostas paralelas ao lado maior da praça, e em geral com o uso da pedra portuguesa sempre nas cores brancas e pretas, acentuam sua horizontalidade que só é rompido pelos grandes canteiros e pelos bancos contínuos.

\footnotetext{
${ }^{4}$ Ver a respeito PAIVA, K. F. \& CAPELLO, M.B. C. A Praça Sérgio Pacheco: uma proposta de Ary Garcia Roza e Roberto Burle Marx para o "Coração da cidade" de Uberlândia/MG, Colóquio As Praças nas cidades 
"A planta é a geradora" (LE CORBUSIER, 1973), e a o concebê-la busca um "ritmo claro e não uma aglomeração incoerente" onde o espaço e volume compõem o sentido de conjunto acentuado em função da marcante paginação de piso. A convergência das esquinas para o centro convida o pedestre, ficando os passeios laterais como continuidade do desenho urbano.

Grandes canteiros, interceptados por bancos contínuos, retilíneos ou levemente sinuosos, cujo acesso é feito por discreta pavimentação em placas de concerto e juntas de gramas formam ambientes diferenciados, onde canteiros menores com formas afiladas e aerodinâmicas, ou a presença da água trará um ritmo claro e funcional incorporado aos pequenos jardins mais elaborados.

Coury vai dispor os equipamentos comunitários, em ambientes, sem obstruir as linhas de comunicação espontâneas ou o centro livre. Esses ambientes diferenciados, com grandes canteiros, enquanto função qualifica o espaço aberto, criando um ambiente definido e mais delimitado, ao mesmo tempo em que pode acomodar o sanitário público ou a concha acústica, bancos ou estátuas, ou mesmo um pequeno jardim junto ao espelho d'água onde reflete a cabeça esculpida em bronze do presidente Juscelino Kubitschek.

A conseqüente leveza é reforçada pelo espelho d'água, que separa a platéia do palco, que tem um acesso pelo lado posterior da concha e outro acesso por duas rampas externas laterais ao palco, totalmente integradas ao conjunto.

A circulação é importante no partido adotado, dando liberdade ao pedestre, e buscando soluções para estacionamentos de automóveis, com ousadas propostas presentes em praças de pequeno ou grande porte. O carro não é ignorado e sim incorporado, de maneira que não descaracterize a conotação de praça, onde a integração social da coletividade é celebrada.

Quando a circulação se apresenta enquanto passeio externo, soluciona o estacionamento diagonal em 450, ou como um convite nas quatro esquinas para 0 "centro livre" direcionando os fluxos para ambientes delimitados, possível de contatos mais próximos, em pequenos nichos, subsidiado pelo ambiente principal, que obviamente é o centro da praça.

Os caminhos para pedestres cruzando diagonalmente a praça contrastando com as ruas tradicionais enfatizam a apreensão visual de todo o conjunto e sua vocação utilitária, de distribuidora de fluxos: "(...) o traçado do ruamento interno, abrindo-se

de origem portuguesa: Perspectivas históricas e contemporâneas, ISCSP, Lisboa, 14 e 15 de Nov/ 2011. 
duas vias em forma de xis, para trânsito de pedestres e no centro ficará então uma área de forma circular" ${ }^{\prime \prime}$.

Esta afirmação de Coury reforça a natureza dos indivíduos enquanto usuários, ir ali ou aqui, ou permanecer, como melhor lhe convier, e justifica sua defesa: "a praça também é atalho, é cortar caminho". Estas vias funcionam como distribuidora de fluxos, e estão sempre a convidar para o interior da praça, enfatizando a visualização.

A visualização é determinante na mobilidade física e social do usuário, onde a exploração estética de recursos formais e materiais se traduz em sua organização e reflete na apropriação do usuário. É o uso que dinamiza o espaço. Antes de ser um "cartão postal" como um marco representativo do poder de uma sociedade, a praça foi proposta para ser usada ou vivida como ambiente.

A convergência das esquinas para o centro convida o pedestre, ficando os passeios laterais em algumas praças como continuidade do desenho urbano, em outras praças o passeio-alameda se configura, chegando mesmo a não existir e se transformar em um grande canteiro, um "pequeno bosque."

Na pavimentação utiliza a pedra portuguesa ao trabalhar a superfície em faixas brancas e pretas dispostas paralelas e longitudinalmente à praça, acentuam sua horizontalidade, que só é rompido pelos grandes canteiros e pelos bancos contínuos.

Esta paginação torna-se constante em seus projetos, não só de praças públicas, mas em espaços privados. A integração interior/exterior, casa/rua, vai estar presente em várias residências, onde usará a paginação em faixas estendidas dos passeios frontais, aos acessos, jardins internos e/ou posteriores.

Os volumes edificados, concha acústica, fonte, sanitários, bancos, e espelhos d'água, foram organizados sempre de tal maneira que definem locais específicos. A concha acústica, colocada no eixo central de um dos lados de menor largura da praça, onde em geral o sol também se põe se destaca por sua proporção e elevação em relação ao solo, artifício utilizado constantemente em seus projetos residenciais, e se projeta sobre um espelho d'água, atuando como referencial ou pano de fundo para o centro livre. Seu nível mais elevado confere a ela uma predominância hierárquica em relação ao espaço circundante.

A fonte, um elemento significativo em todas as épocas, se apresenta em algumas praças como um elemento plástico mais audacioso e tecnicamente mais elaborado, com tabuleiros aéreos, som, luz, e plantas ornamentais, em outras praças a simplicidade de um esguicho em um espelho d'água forma um conjunto harmonioso

\footnotetext{
${ }^{5}$ João Jorge Coury, In jornal O Correio, sem data
} 
com os jardins circundantes. Seja qual for a opção de projeto, sua disposição vai estar sempre caracterizando o ambiente onde foi disposta.

A fonte sonoro-luminosa é o elemento plástico mais audacioso. Um prato de concreto iluminado, assentado sobre um volume triangular envolvido por um espelho d'água. Seus volumes se destacam por suas superfícies tecnicamente trabalhadas. O prato é extremamente liso. Contrasta com a textura áspera e com os elementos vazados emoldurados da base que o sustenta. As bordas do espelho d'água dispostos geometricamente, interagem com espécies vegetais, criando um jardim, que forma um conjunto harmonioso com os jardins circundantes. É a fonte que caracteriza esse ambiente como ponto de atração (FIGURA 4).

A água, elemento marcante em nossos espaços públicos, vai estar presente na fonte, mas também em espelhos d'água, dispostos geometricamente, onde suas bordas interagem com espécies vegetais criando pequenos jardins, e dando leveza à algumas construções, ou valorizando uma escultura ou um monumento.

Os bancos sempre foram elementos importantes na trama urbana, nas praças sempre funcionaram como um convite ao descanso para os pedestres, ou um refúgio para um contanto mais próximo. A inserção dos bancos contínuos, coletivos, de moderno despojamento, sem ornato; estão associados ao próprio traçado, situados com uma plasticidade rigorosa, oferece aos caminhantes amplas e surpreendentes perspectivas. Os bancos coletivos vão oferecer uma nova forma de convivência urbana.

Os bancos em alguns momentos atuam como elementos de direcionamento de fluxos, em outros como delimitadores, quanto vão configurar um sentido espacial a esses lugares, criando, zonas movimentadas, e pontos de encontros, ou zonas de quietude e contemplação.

A intercepção dos bancos nos grandes canteiros, retilíneos ou levemente sinuosos, cujo acesso é feito por discreta pavimentação em placas de concreto e juntas de grama, que acompanha a disposição dos bancos, proporciona ambientes diferenciados, e integra o usuário como se este estivesse em um pequeno bosque . 


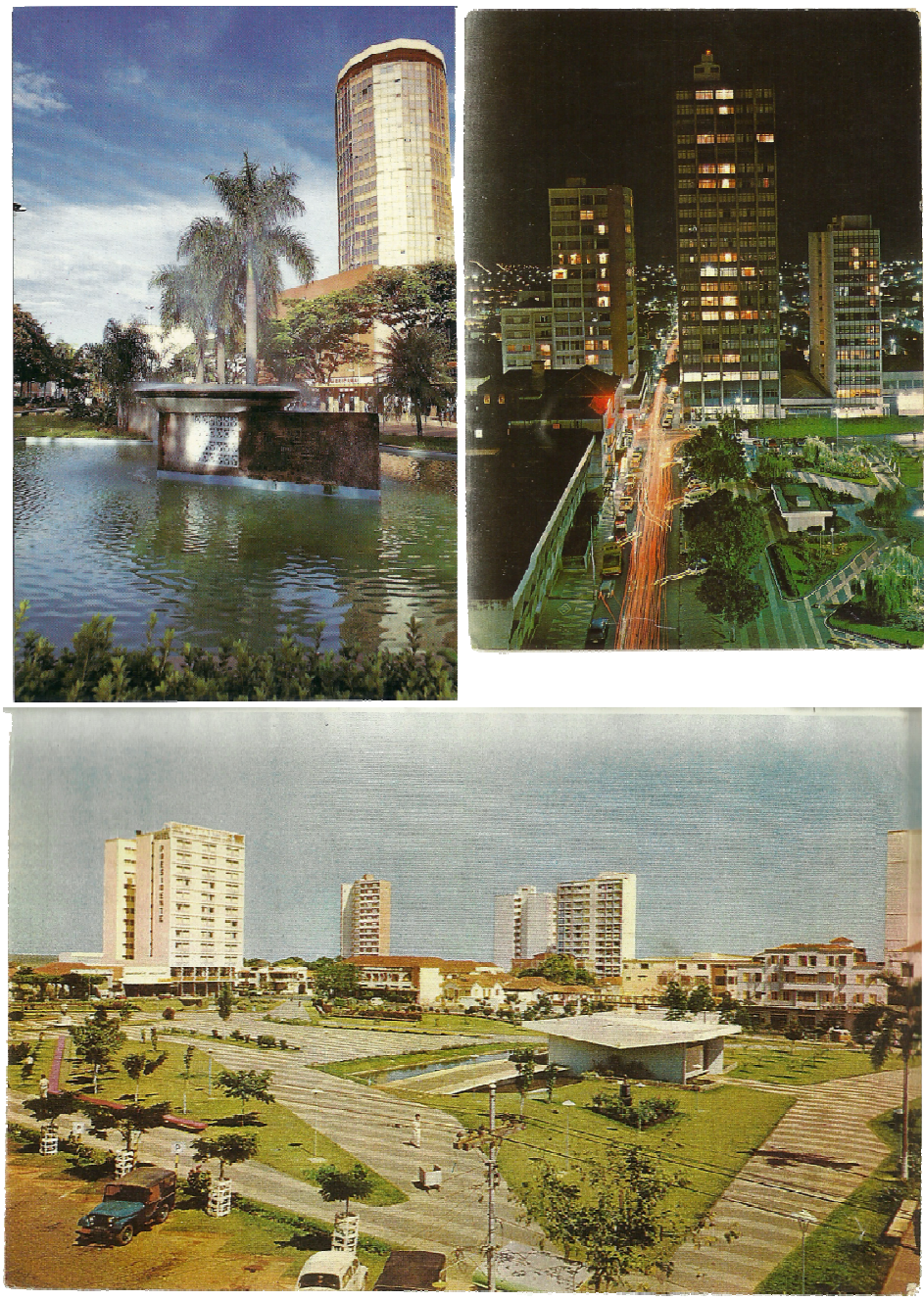

FIGURA 4 - Praça Tubal Vilela - 1a Foto: fonte sonora luminosa, 2010 - $2^{\text {a }}$ Foto: vista noturna, 1988 - e 1964 - vista geral.

FONTE: Cartão Postal: Acervo da autora.

A utilização de bancos contínuos, coletivos em substituição aos tradicionais, com o uso do concreto, de moderno despojamento, sem ornato, inova ao propor dimensões, de até $50 \mathrm{~m}$. Quanto à sua implantação, estão associados ao próprio traçado urbano. A maioria penetra nos grandes canteiros, exceção feita aos bancos centrais, que auxiliam na delimitação física do centro livre, direcionando o fluxo do caminhante. É a 
partir desde momento que Coury utilizará o banco contínuo em jardins residenciais, conforme enfatizado anteriormente.

As placas de concreto também vão estar presentes nas circulações que levam aos outros equipamentos de usos ou de serviços. É o caso dos sanitários públicos, quando existentes e que de uma maneira geral vão estar inseridos na parte posterior da concha acústica, ou em um semi subsolo nas fontes. A única exceção acontece na Praça Tubal Vilela, onde o sanitário é um elemento autônomo, inserido em um grande canteiro lateral definindo um pequeno jardim elaborado circundante.

Esta função hierárquica determina uma heterogeneidade para a praça, cria setores diversificados e ordenados, com pontos de atração, que pode ser a concha acústica, a fonte, os bancos, os espelhos d'água, seu centro livre ou a vegetação. As estruturas espaciais de formas e tamanhos variados, perpetuados pelo traçado cartesiano são tratadas a partir de uma postura projetual onde a vegetação é um elemento qualificador do espaço.

A escolha do elemento construído e do vegetal está relacionado ao programa da praça e ao usuário, tanto nos grandes, como nos pequenos porte, sempre tentando atingir um equilíbrio na solução encontrada. A geometrização é uma característica marcante, utilizando retas, ângulos, polígonos, etc., valorizando pontos de interesse e estabelecendo referências, em busca desse equilíbrio de interação mútua entre usuário e vegetação.

\section{Algumas Considerações}

Aos projetos de pequeno porte, além das praças executadas devem-se incluir os jardins residenciais, de fundamental importância dentro do conjunto de obras de Coury, para se compreender sua visão ideológica com a vida moderna e o urbano moderno, já que a solução de um jardim exige adequações funcionais e técnicas, ao mesmo tempo em que permite maiores liberdades formais.

Atualmente a Praça Tubal Vilela faz parte do patrimônio edificado da cidade. Tombado pela Lei Municipal no 9.676 de 22 de novembro de 2004 por ser um exemplar do urbanismo moderno da cidade e região e ter sido estrategicamente concebida em meio às principais vias de circulação, efetivando sua importância político-social ao longo do século XX. A expansão do centro para outras áreas da cidade não enfraqueceu sua localização, já que a mesma concentra atividades diversificadas com múltiplos usos, sendo que, a Praça Tubal Vilela continua sendo a principal praça "o coração da cidade", "cartão de visita" com forte significado simbólico para a cidade. 
A leitura do embasamento teórico de João Jorge Coury hoje pode parecer um tanto "sem novidades". Isto acontece porque os preceitos modernos atualmente são inerentes à maneira de projetar, mas se contrapostos a Uberlândia, ao Triângulo Mineiro, e porque não à maioria das cidades brasileiras, à época, recém saídas do ecletismo, veremos quanto de inovação estes representavam.

Referências Bibliográficas

ARANTES, Otília B. (1993). O lugar da arquitetura depois dos modernos. São Paulo: Nobel/Edusp.

GOMES, M. A. de F. (ORG.) (2009). Urbanismo na América do Sul: circulação de idéias e constituição do campo, 1920 - 1960. Salvador: EDUFBA.

GUERRA, M. E. A. (1998). As "Praças Modernas de João Jorge Coury no Triângulo Mineiro, Dissertação de Mestrado, EESC/USP, São Carlos.

(2011). A Praça Tubal Vilela em Uberlândia/MG em três Momentos. Colóquio As Praças nas cidades de origem portuguesa: Perspectivas históricas e contemporâneas, In anais, ISCSP, Lisboa, Portugal14 e $15 /$ nov/2011. (2008) Vilas Operadoras de Furnas nas bacias dos Rios Grande e Paranaíba - da concepção à atualidade, Tese de Doutorado, IG/UFU, Uberlândia.

GUERRA, M.E.A. \& RIBEIRO, P.P.A. (2002). Arquiteto João Jorge Coury, In: Revista Aqui, no 3, abril/2002, p.16 - 26, IAB- Instituto de Arquitetos/MG, Belo Horizonte: AP Cultural.

LOPES, Valéria M. Q. C.(2006). Caminhos e trilhas: Transformações e apropriações da cidade de Uberlândia, Uberlândia: EDUFU MACHADO JUNIOR, Juscelino H. C. (2011). Sob a Perspectiva de síntese das Artes: a obra de J.J. Coury e Geraldo Queiróz no Triângulo Mineiro, In anais: 20 Seminário Ibero-americano - Arquitetura e Documentação, UFMG, Belo Horizonte, 02 a 04 de nov/ 2011.

MESQUITA, Adaílson P. \& SILVA, Hermilton Q. (2006). As linhas do tecido urbano: o sistema de transportes e a evolução urbana de Uberlândia/MG. Uberlândia: G. Roma.

PAiVA, K. F. \& CAPELlO, M.B. C. A Praça Sérgio Pacheco: uma proposta de Ary Garcia Roza e Roberto Burle Marx para o "Coração da cidade" de Uberlândia/MG. Colóquio As Praças nas cidades de origem portuguesa: Perspectivas históricas e contemporâneas, ISCSP, Lisboa, 14 e 15 de nov/ 2011. 
RIBEIRO, P.P.A. (1998). A Difusão da Arquitetura Moderna em Minas - 0 arquiteto J.J. Coury em Uberlândia, Dissertação de Mestrado, EESC/USP, São Carlos.

SAlgueiro, H. A. (1997). Engenheiro Aarão Reis: O Progresso como Missão.

Belo Horizonte: Fundação João Pinheiro. 